\title{
Critical Success Factors in Implementing BPR in a Government Manufacturing Unit - An Empirical Study
}

\author{
S K Dubey ${ }^{1} \&$ Sanjeev Bansal ${ }^{1}$ \\ ${ }^{1}$ Amity Business School, Amity University, Noida, India \\ Correspondence: S K Dubey, Amity Business School, Amity University, Noida, India. Tel: 91-931-292-5642. \\ E-mail: skdubey@amity.edu
}

Received: November 5, 2012 Accepted: December 25, 2012 Online Published: December 28, 2012

doi:10.5539/ijbm.v8n2p107 URL: http://dx.doi.org/10.5539/ijbm.v8n2p107

\begin{abstract}
The purpose of this paper is to identify the critical success factors for Business Process Reengineering implementation of a government manufacturing unit. A questionnaire was designed and was mailed to government manufacturing units. The data extracted from the replies were used to perform the empirical analysis. Based on the results, a conceptual model was prepared. Hypotheses were developed to evaluate the impact of Critical Success Factors constructs on the overall performance of the manufacturing unit. The empirical analysis reveals that there is a substantial positive effect of the Critical Success Factors on the overall performance of the government units. Overall, the results showed that there is lack of coherency in implementing Critical Success Factorss in government units because of certain handicaps under which government agencies operate. Ironically these handicaps are practically unknown to private sector. Notwithstanding this, the government units can improve performance by adopting and adapting methodologies, some goals that have proven in private sector business. The research is subject to the normal limitations of survey research. The research can make a useful contribution to government units.
\end{abstract}

Keywords: business process reengineering, critical success factors, performance, SPSS

\section{Introduction}

In 1980s and 1990s, TQM movement emphasized on process focused change. Raff and Beedon (1994); Hodgson (1994) observed that sufficient literature is available to show wide application of TQM in non profit and public organizations. However, radical changes through BPR have not been accepted by public organizations. Hammer \& Champy (1993), in a survey, observed that approximately 70 percent of all private business in US and Europe were using BPR to have performance improvement. The authors also observed that the failure rate of reengineering attempts were high - to the extent of 70 percent. Reengineering also required high investment. 'Fear of failure', 'high risk of investment', and 'bureaucratic set up' could have kept public sectors away in adopting radical changes through BPR.

This research identifies CSFs of BPR practices, studies the relationship among CSFs and develops a conceptual model that can investigate the effectiveness of organizational performance through critical success factors (CSFs) in government organizations while going through implementing radical changes through adopting Business Process reengineering (BPR). BPR success has been considered the extent to which the project accomplished a list of desirable goals and objective as well as instrumental in improving specific dimensions of organization performance. The research provides empirical insights into the relationship between CSF of BPR practices and overall performance of government manufacturing organization. The objective of the research is:

1) To identify the CSFs of BPR practices in government owned manufacturing unit; and to classify the identified CSFs into various categories by doing factor analysis.

2) To find out the relevance of each CSF and establish relationships among CSFs.

3) To identify key performance indicators and to develop a conceptual model of performance indicators linked with CSFs in the control and monitoring of CSF.

\section{Literature Review}

BPR is concerned with making significant, radical changes to a company based on the business process. 
Hammer \& Champy(1993, page 35) defined BPR as "Reengineering is the fundamental rethinking and radical redesign of business process to achieve dramatic improvements in critical, contemporary measures of performance such as cost, quality, service and speed". Cohen and Brand (1993) in their research on "TQM in Government": note that "TQM is not magic". They argue that by effective employment of human resources, government performance can be improved by continuous improvement of operating processes. Huq (2005), Kotey (2005), Tamimi (2003) observed that the barriers to incremental/radical changes are linked to effective change transformation. A comprehensive review of literature has resulted in identifying 27 significant barriers, which can be grouped into five categories: top management barriers, planning barriers, operational barriers, resources barriers, and cultural barriers (Black and Porter (1996), Oakland (1997)).

BPR's implementation is perceived difficult. Many unsuccessful experiences have been reported in literature. Successful implementation of BRP involves understanding and deployment of several critical success factors. To date, different researchers have defined different CSFs for successful BPR implementation. Jamali, Abbaszadeh, et at (2011) identified seven CSFs - Collaborative working environment, top management support and commitment, IT infrastructure, training, less bureaucratic structure, culture, adequate financial resources. In government organizations, it is important to understand on how various functions are coordinated while participating in the business processes. (Grover et al., 1996) observes that the organizational functions interact as functional coupling. BPR should create cross functional teams that would collaborate with CSFs to minimize the chances of failure of implementing radical changes.

The primary objective of BPR is to make organizations more competitive by optimal utilization of resources, reducing costs, shortening product development cycles, improving quality, and satisfying customers (Vantrappen, 1992). According to Chang (1994), BPR's distinguishing characteristics are radical change, cross-functionality, operating across organizational units, breaking outdated paradigms, and involves innovative application of technology. The change process challenges the old ways and proposes new process. The change process focuses on objectives and end results. It challenges the old ways of doing process, and proposes new methodologies. It identifies time as a prime competitive factor. It leads to value-added element for every activity, ensures quality at the source, planning for an end-to-end solution. Al - Mashari \& Zairi (2000) opines that organization undergoing radical change process would set aggressive goals with updated technology, empowering people, building consensus on accepting changes, change processes that are necessary to company's success. Davenport (1993) views that BPR is setting new way of business processes, rather than concentrating on business functions or other organizational entities. Based on this literature survey, a list of potential BPR projects goals and objectives were collected, which were reframed keeping the requirement of government organization.

CSF approach is "the determination of the set of factors that the manager considers critical for success. CSF can be characterized as: internal (endogenous) or external (exogenous) to the organization. Pinto and Slevin (1987, p22) defined critical success factors as "factors which, if addressed, would significantly improve project implementation chances". According to Flynn and Arce (1997, p. 312), "an internal CSF has related actions taken within the organization, while an external CSF has related actions performed outside the organization". Internal CSF related to situations or issues within managers control while external CSF may not be controlled. This dimension is very important in order to collect the information from the proper sources of information. According to (Peffers et al. 2003, p. 55), "senior managers have found CSF to be appealing for IS planning because they help justify the development of strategically important new systems, the benefits of which may be hard to quantify". In this study internal CSF of government organizations have been examined to evaluate the performance indicator.

There are many possible business benefits from reengineering, which translate into improved company performance. Therefore, the company performance is the ultimate measure and dependent variable for studies assessing the overall benefits from substantial reengineering projects. According to Birch (2000, p. 5), a performance measure or performance indicator "is composed of a number and a unit of measure. The number gives us a magnitude (how much) and the unit gives the number a meaning (what). Performance measures are always tied to a goal or an objective".

Government organizations are continuously under pressure to answer the tax payers (customers) regarding the performance improvement of its services. The step wise improvement in services and products of public sector is no longer sufficient to satisfy the customers due to better services provided by private sector companies which have been outsourced to them by government. The TQM techniques, such as - quality management, six sigma, Kaizen, Total Productive Maintenance (TPM) and others focus on improving existing processes, which are outdated and outmoded. Therefore, these tools do not add value to the processes. The only means to come out of this situation is to adopt radical approach to BPR. 
The customer's confidence in public sector's product or services are the competitive dimensions which can be referred as Performance Objectives, Customer Requirement, Strategic Choice Attributes, Competitive Capabilities, and Operational Priorities (Chan 2005). Yusuf and Aspinwall (2000) identified CSFs for TQM implementation as management leadership, continuous improvement programme, measurement feedback, systems and processes, resources, work environment and culture. These are basic ingredients for implementation change management. These factors along with operation effectiveness, strategic planning, and external interface management can be considered as important CSFs for managing radical changes through BPR.

As discussed above, government organizations should radical redesign their processes to achieve dramatic enhancement in their performance: such as optimization in resource utilization, cost, quality, reduced time of service, speed and customer friendly service. To achieve this, various alternatives of BPR's CSFs should be analyzed to assess their impact on performance as a whole organization. This requires an appropriate performance model which will help to gain insights into the concept of interaction of CSFs enabling the overall application of BPR.

Performance management is a multidisciplinary activity. Performance management is about managing resources, operations, development of appropriate strategy within an organization. Issues such as innovation, and risk taking are important to bring about enhanced performance. Various management techniques, approaches, and models have been developed independently. Strategy has been concerned with developing plans to deliver future objectives. Financial and management accounting are being utilized in measuring and controlling the financial performance of organizations. Operations management focuses on improving throughput and efficiency. In order to measure actual performance of an organization, these distinct disciplines have to be integrated into a multidisciplinary approach to managing performance. Neely (1998) identifies performance as multidimensional measure consisting of three inter-related elements: individual measures (operations) that quantify the efficiency and effectiveness of actions, a set of measures (change management) that combine to assess the performance of an organization as a whole, and a supporting infrastructure (systems) that enables data to be acquired, collated, sorted, analyzed, interpreted and disseminated.. Ittner, Larcker and Randall (2003), Gates (1999) and Otley (1999) included development of strategies or objectives. Thus, performance management is a collection of activities including the setting of objectives or strategies; identification of action plans/decision making; execution of action plans and the assessment of achievement of objectives/strategies (Steers, 1977; Venkatraman \& Ramanujam, 1986; Snow \& Hrebniak, 1980). In government organizations, most of the performance measures are different than what is being applicable to private sectors. In government organizations, there is more emphasis on throughput and shop floor efficiency. These were deliberated upon the senior management of the select organizations. From the deliberation, five key performance dimensions have been identified for the select organization, which are indicated at serial No. 37 to 41 in Table 1 . The result of a survey to understand the objectives of BPR in a government organization is tabulated in Table 4.

Table 1. Classification of critical success factors - BPR

\begin{tabular}{clrc}
\hline S. No. & \multicolumn{1}{c}{ Critical Success Factor } & Mean & S. D. \\
\hline & Strategically Factors & & \\
1 & Leadership & 4.55 & 0.67 \\
2 & Work environment and culture & 4.25 & 0.88 \\
3 & Top management support & 4.22 & 0.87 \\
4 & Quality improvement systems & 4.13 & 0.75 \\
5 & Technology transfer and absorption & 4.25 & 0.8 \\
6 & Induction of IT tools and induction of ERP software & 2.37 & 1.14 \\
7 & External interface management & 4.19 & 0.73 \\
& Radical Change Factors & & \\
8 & Management vision & 4.01 & 0.96 \\
9 & Acceptance and performance of Change management & 2.22 & 1.24 \\
10 & Customers' involvement in viewing product quality \& development \& customer & & \\
& management & 2.87 & 1.32 \\
\hline
\end{tabular}




\begin{tabular}{|c|c|c|c|}
\hline 11 & Empowerment and collaborative workers & 2.75 & 1.18 \\
\hline 12 & Response to changing volume and product mix & 3.28 & 1.4 \\
\hline 13 & People skill interchangeably & 4.5 & 0.7 \\
\hline 14 & Changing performance system from 'Man - hr' accounting to Budgeting system & 2.53 & 1.15 \\
\hline 15 & Investment in R \& D & 2.26 & 1.08 \\
\hline 16 & Indigenization programme under Manufacturing Unit & 1.75 & 1.4 \\
\hline 17 & Supplier partnership & 4.11 & 0.81 \\
\hline 18 & Supplier relationship & 4.52 & 0.67 \\
\hline 19 & Supplier quality and assessment of supplier performance & 4.19 & 0.75 \\
\hline 20 & Resource value addition process & 4.46 & 0.74 \\
\hline \multirow[t]{2}{*}{21} & New process, product and service design development & 4.41 & 0.73 \\
\hline & Operational factors & & \\
\hline 22 & Implementation, Control, and monitoring of new process as per schedules & 3.12 & 1.42 \\
\hline 23 & Customer management & 4.17 & 0.73 \\
\hline 24 & Productivity improvement & 4.38 & 0.71 \\
\hline 25 & Training & 4.11 & 0.77 \\
\hline 26 & Quality policy to improve product quality & 4.45 & 0.65 \\
\hline 27 & Communication - sharing information willingly & 4.25 & 0.83 \\
\hline 28 & Team building & 3.33 & 0.93 \\
\hline 29 & Resource preservation and utilization & 4.45 & 0.77 \\
\hline 30 & Response to crisis & 4.35 & 0.75 \\
\hline 31 & Reduce response time, cost by automation & 4.27 & 0.83 \\
\hline 32 & Customer satisfaction & 3.97 & 0.85 \\
\hline 33 & Managing resistance to change & 4.35 & 0.72 \\
\hline 34 & Simplification of material flow, logistics, and other distinct operations & 4.05 & 0.78 \\
\hline 35 & Desire for continuous performance improvement & 4.03 & 0.84 \\
\hline \multirow[t]{2}{*}{36} & Creating an enabling chart that describes BPR process & 3.85 & 0.95 \\
\hline & Non - Financial performance Factors & & \\
\hline 37 & Optimal utilization of man - hours & 4.19 & 0.89 \\
\hline 38 & High technical reliability of products & 4.24 & 0.88 \\
\hline \multirow[t]{2}{*}{39} & Timely meeting customer's requirement & 4.38 & 0.76 \\
\hline & Financial Performance Factors & & \\
\hline 40 & Effective utilization of budgets at Cost centres & 4.04 & 0.99 \\
\hline 41 & Optimum utilization of resources - within the overall budgets & 3.92 & 0.81 \\
\hline
\end{tabular}

\section{Research Design}

\subsection{Sample}

The research was initially planned to examine CSFs of BPR implementation in defence manufacturing units. These units, being in very small numbers, could not make a substantial sample size. Since the Public sector units have similar organization structure and operational functioning as of the defence units, the PSUs were also included in the target sample frame The point of entry into the organizations participating in this research was through mailing questionnaires both in public sector and defence units. It was requested that the questionnaire be completed by managers on shop floor (termed as executives in the questionnaire), or by managers involved in planning and monitoring actions (termed as managers in the questionnaire), or by top hierarchal managers, or by 
all of them. Cronbach's alpha coefficient was used as a measure of reliability, which is 0.97 . Therefore, the scales are satisfactory for subsequent analysis.

In order to construct the questionnaire which is appropriate to the research, extensive literature review was carried out. The studies of Al-Mashari and Zairi (1999), Ahmad et al, (2007); and Jinjiri, Rizal, Norelena (2012) were used in initial formulation of questionnaire which was further modified by discussing with experts from academics and the top management of the government units. The questionnaire consists of 41 statements grouped under strategy, radical changes, operations and performance. These are presented in Table -1 with individual item rating. All the items in the questionnaire were measured with a five-point Likert scale ranging from very low (1) to very high (5) to ensure consistency and the ease of data computation. The data collected were analyzed by using SPSS. Factor analysis was carried out to identify underlying variables that explain the pattern of correlations within the observed variables. It was also used to generate hypothesis regarding functioning of the conceptual model. Finally, regression analysis was carried out to determine the relationship between the identified CSFs and organizational performance.

\section{Results and Analysis of the Research Study}

1) Profile of the Respondents Table 2 summarizes the demographic profile of the respondents. A total of 325 responses (out of 700) were received within the specified time. 23 responses (invalid response -10 , missing data - 13) were discarded. Thus the sample represents 43.4 percent response rate which is considered satisfactory. The responses indicated that a majority of the respondents ( 82 percent) were from executives who were working on shop floor - thus aware of shop floor problems. 92 percent of respondents were graduate engineer; 18 percent of the respondents had further done MBA programme. Around 46 percent of the respondents were further trained by the organization on specific disciplines.

Table 2. Demographic profile of respondents

\begin{tabular}{|c|c|c|}
\hline S. No. & Factors & Percent \\
\hline \multicolumn{3}{|l|}{ Age } \\
\hline 1 & $20-29$ & 8.48 \\
\hline 2 & $30-39$ & 24.83 \\
\hline 3 & $40-49$ & 48.01 \\
\hline 4 & $\geq 50$ & 18.68 \\
\hline \multicolumn{3}{|l|}{ Sex } \\
\hline 5 & Male & 83.44 \\
\hline 6 & Female & 16.56 \\
\hline \multicolumn{3}{|c|}{ Qualification } \\
\hline 7 & Graduate & 2.65 \\
\hline 8 & Engineering & 97.35 \\
\hline \multicolumn{3}{|c|}{ Additional Qualification } \\
\hline 9 & PGDM/MBA & 26.16 \\
\hline \multicolumn{3}{|c|}{ Position held in Organization } \\
\hline 10 & Non - executive & $\mathbf{0}$ \\
\hline 11 & Executive & 82.45 \\
\hline 12 & Managerial & 17.55 \\
\hline \multicolumn{3}{|c|}{ No. of Years of Service } \\
\hline 13 & $\leq 5$ Years & 9.93 \\
\hline 14 & $6-10$ Years & 9.6 \\
\hline 15 & $>10$ Years & 80.46 \\
\hline \multicolumn{3}{|c|}{ Any Specialized Training } \\
\hline 16 & Equipment Specialization & 45.73 \\
\hline
\end{tabular}


2) Reliability The internal consistency is usually calculated using an alpha coefficient, which measures the interrelationship between items in the questionnaire (Cortina, 1993). Nunally (1978) argued that a reliability of 0.70 or higher is acceptable. The Cronbach alphas for all ranks are higher than 0.70 (actual score was 0.76 - Reliability results are shown in Table 3). This analysis indicates that the scales used in the study are reliable. (Terziovski et al., 1997).

Table 3. Measurement of cronbach's alpha value - reliability parameter

\begin{tabular}{clcc}
\hline S. No. & \multicolumn{1}{c}{ Factor } & No. of Constructs & Cronbach's Alpha Value \\
\hline 1 & Strategical Constructs & 5 & 0,72 \\
2 & Radical Changes Constructs & 3 & 0.75 \\
3 & Operations Construct & 4 & 0.77 \\
4 & Performance Constructs & 2 & 0.74 \\
5 & Overall Constructs & 41 & 0.77 \\
\hline
\end{tabular}

Table 4. BPR project goals and objectives

\begin{tabular}{clcc}
\hline S. No. & \multicolumn{1}{c}{ Expected Goals/Objectives } & Mean & S.D \\
\hline 1 & $\begin{array}{l}\text { Formulating practical targets (business process goals), and focus on achieving } \\
\text { end results and objectives. }\end{array}$ & 4.15 & 0.88 \\
2 & $\begin{array}{l}\text { Optimally utilizing the resources and reducing costs, leading to reduction in } \\
\text { operating budget. }\end{array}$ & 3.12 & 0.95 \\
3 & Increase own credibility by improving quality. & 2.84 & 0.65 \\
4 & Redesign end-to-end processes important to the company's success & 3.24 & 0.75 \\
5 & Used time as a competitive weapon (decreased cycle time and optimal man - & 3.11 & 0.79 \\
& hour utilization). & 2.95 & 0.65 \\
6 & Transferring and absorbing right technology. & 3.13 & 0.91 \\
7 & Improve information technology base and inculcate transparency. & 2.95 & 0.79 \\
8 & Emphasized the value-added element at every activity. & 3.56 & 0.98 \\
9 & Built consensus on making changes. & &
\end{tabular}

3) Validity It was assessed along three dimensions; content, construct (indicating how well the results obtained from the use of the measure fits the concepts around which it is designed), and criterion validity (indicating the ability of some measures to correlate with other measures of the same construct). The questionnaire used in this study was based on a comprehensive literature review and discussions with company's top management. This helped to establish content validity. Criterion validity was established through the multiple regression output as dependent variables were explained by independent variables. Construct validity was evaluated using principal components factor analysis (Hair et al., 1992), which was established as no items fell below the 0.45 factor loading level (Table 7 ).

Table 7. Factor analysis of reengineering constructs independent variables

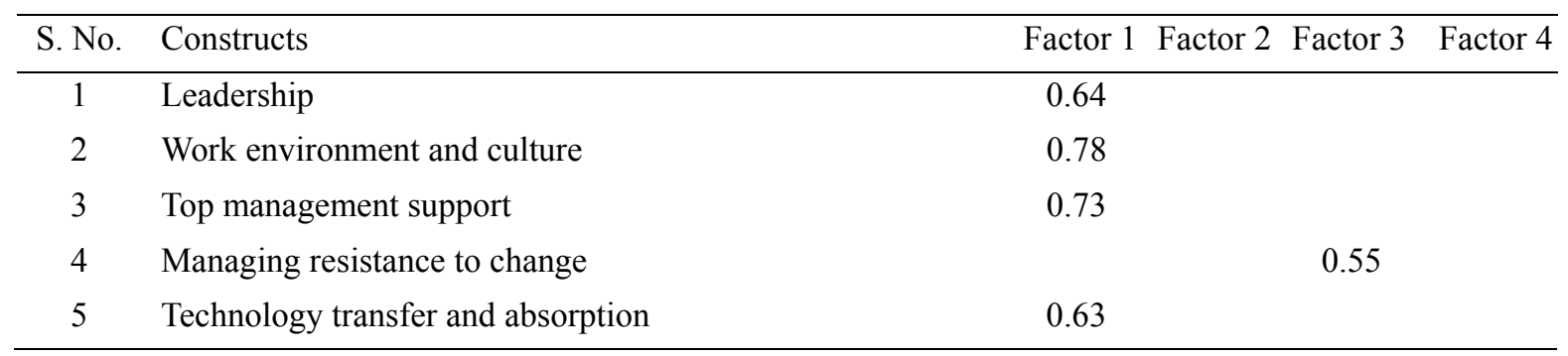




\begin{tabular}{|c|c|c|c|c|c|}
\hline 6 & $\begin{array}{l}\text { Customers' involvement in viewing product quality \& } \\
\text { development \& customer management }\end{array}$ & & 0.95 & & \\
\hline 7 & Induction of IT tools and induction of ERP software & 0.46 & & & \\
\hline 8 & High technical reliability of products & & & & 0.77 \\
\hline 9 & $\begin{array}{l}\text { Optimum utilization of resources - within the overall } \\
\text { budgets }\end{array}$ & & & & 0.61 \\
\hline 10 & Customer satisfaction & & & 0.98 & \\
\hline 11 & Management vision & & 0.96 & & \\
\hline 12 & Supplier partnership & & 0.81 & & \\
\hline 13 & Quality policy to improve product quality & & & 0.95 & \\
\hline 14 & Training & & & 0.71 & \\
\hline
\end{tabular}

4) Factor Analysis \& Constructs of BPR CSFs In order to determine the number of factors needed to represent the data, 41 items (variables) measuring the BPR CSFs in the research model were subjected to principal component factor analysis. Table 5 indicates that fourteen factors out of 41 critical success variables were extracted with an Eigen value greater than 1 /or near to 1 for each, and covering 69.82 percent of the total variance. Based on the items loading on each factor, these factors were labelled as "strategic factors" (factor 1), "radical change factors" (factor 2), "operational factors" (factor 3), and "performance factors (factor 4). None of the items (variables) were dropped in the analysis because all factor loadings exceeded 0.50 on its own factors. This analysis shows that the average variances extracted (AVE) of the individual constructs are higher than the shared variances between the constructs, thus confirming discriminate validity.

Table 5. Critical success factors for bpr - results of factor analysis

\begin{tabular}{clccc}
\hline \multirow{2}{*}{ Component } & & $\begin{array}{c}\text { Initial } \\
\text { Eigenvalues(a) }\end{array}$ & $\begin{array}{c}\text { \% of } \\
\text { Variance }\end{array}$ & Cumulative \% \\
\hline 1 & Leadership & 5.37 & 15.35 & 15.35 \\
2 & Work environment and culture & 2.95 & 8.42 & 23.77 \\
3 & Top management support & 2.22 & 6.33 & 30.10 \\
4 & Managing resistance to change & 1.84 & 5.27 & 35.37 \\
5 & Technology transfer and absorption & 1.81 & 5.18 & 40.55 \\
& Customers' involvement in viewing product quality & & & \\
6 & \& development \& customer management & 1.67 & 4.76 & 45.30 \\
7 & Induction of IT tools and induction of ERP software & 1.51 & 4.30 & 49.60 \\
8 & High technical reliability of products & 1.30 & 3.72 & 53.33 \\
& Optimum utilization of resources - within the overall & & & \\
9 & budgets & 1.13 & 3.22 & 56.55 \\
10 & Customer satisfaction & 1.11 & 3.16 & 59.70 \\
11 & Management vision & 0.94 & 2.69 & 62.39 \\
12 & Supplier partnership & 0.91 & 2.59 & 64.98 \\
13 & Quality policy to improve product quality & 0.87 & 2.49 & 67.47 \\
14 & Training & 0.82 & 2.34 & 69.81 \\
\hline
\end{tabular}

\section{Development of Conceptual Model}

Different techniques and approaches have been developed independently focusing on developing strategy to develop plans to deliver future objectives, measuring and monitoring the financial as well as non - financial 
performance of organizations. In order to conceptualize an unbiased and a true representative of organizational constructs, it is mandatory that performance management from disparate disciplines (strategy, radical changes, and operations) are to be integrated into a multidisciplinary approach. This approach will assist in examining the way in which performance is managed. We examined two basic primary issues - (a) what should be managed, thus indicating how are objectives and strategies identified; (b) and, how to execute these plans? This means that all the factors be examined to establish relationships amongst them to understand their impact on organization's success.

Factor analysis extracted fourteen constructs, which have been further grouped under four factors (Table 6). Three of the factors (strategy. radical changes, operations) are operational in different ways. The translation of coherent effect of strategy constructs, radical changes constructs, operations constructs to a more precise meaning is the key performance indicator. From geometry it is known that triangle does not deform easily, when the lengths of the sides are fixed. It is able to balance the stretching and compressive forces. It is the simplest geometric figure.

Table 6. Realignment of components - factor wise

\begin{tabular}{cl}
\hline Factor & \multicolumn{1}{c}{ Component } \\
\hline & \multicolumn{1}{c}{ 1. Strategic Factors } \\
2 & Leadership \\
3 & Work environment and culture \\
4 & Top management support \\
5 & Technology transfer and absorption \\
& Induction of IT tools and induction of ERP software
\end{tabular}

\section{Radical Change Factor}

6 management

7 Management vision

$8 \quad$ Supplier partnership

\section{Operations}

9 Quality policy to improve product quality

10 Managing resistance to change

11 Customer satisfaction

12 Training

\section{Performance Measure Factor}

13 High technical reliability of products

14 Optimum utilization of resources - within the overall budgets

Keeping these properties in view, we have represented the model by a triangular pyramid. The base of the pyramid represents the organization functioning with respect to its strategy, measures adopted for encountering radical changes, and the operations. The outcome of the actions initiated by the company is its performance, which is represented by the vertex of the pyramid.

Ramamurthy (1995); Beaumont et al. (2002); Brah et al. (2002); and Koh et al. (2007) advocated performance measurement in two dimensions: operational performance and organizational performance. Operational performance is considered primary measures as they are achieved from the actions taken during implementation of BPR (cost and waste reduction, improving the quality of products, improving flexibility, improving delivery performance; and productivity improvement). Organizational performance is secondary measures because they are the consequence of BPR implementation. It indicates the capacity to develop a competitive profile (revenue growth, net profits, profit to revenue ratio and return on assets, and non-financial measures such as investments in $R \& D)$. 
In the current study it is assumed that impact of strategy, implementation of change management, and operations would affect both - the operational performance and the organizational performance. In order to sustain a balanced overall performance; the gains from 'operation' and 'organization' performances should balance out, like of two players in a 'see - saw' game. Any relative imbalance or importance to either of the performances would misbalance the overall performance - like the plank on which two players are playing the 'see - saw' game; thereby would create a imbalanced pyramid which will would negate gains of one from another.

The above concept can be represented by CSFs vectors in a schematic diagram. This model is named as SWATI Model (Strength, Weaknesses, Analysis \& Transformation Indicator Model), as shown in Figure 1. It shows the relationship between each CSF factor and its fundamental relationship. Each factor is connected by a vector which is a true representation of their impact on organizational and operational performance in quantity and its direction. The triangular pyramid shows each CSF and its fundamental relationship with the other CSF. The vectors connecting the CSF are representative of the assumed policies, responsibilities that one CSF has with other CSF, and the information that must be transferred between them. This schematic representation is an indication that BPR implementation is not a linear process of implementation of CSFs. BPR implementation requires a constant change and reconsideration of the company's strategy, operational procedures, and managing change. (Data has been collected to validate SWATI model which will be discussed in a separate research paper.)

The timing relationship of the conceptual model is shown in Figures 2(a) to 2(d). Each of the four triads represents a different phase in the cycle of achieving success in BPR implementation. Figure 1 and Figure 2 lay a clear cut necessity of having a cohesive and synergetic approach in implementation of BPR.

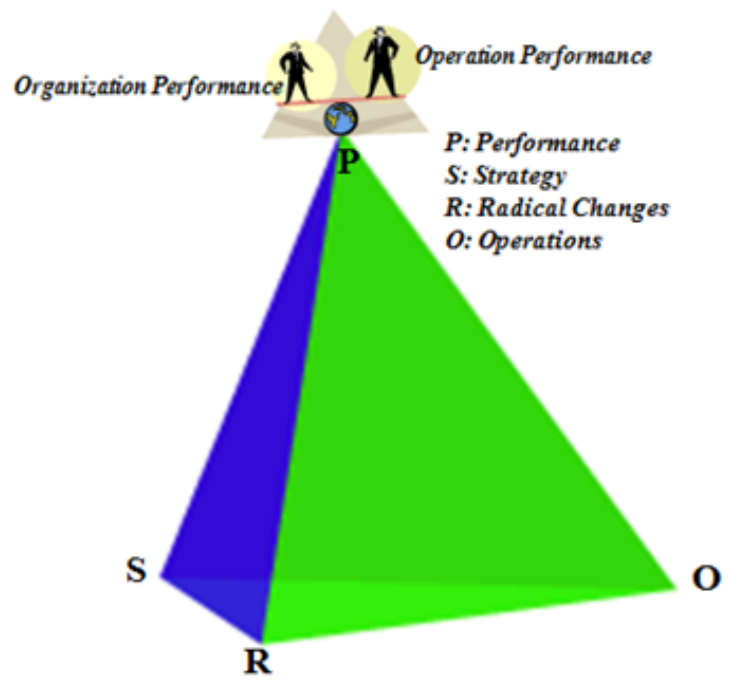

Figure 1. SWATI (strength, weaknesses, analysis \& transformation indicator) model

Strategy (S)

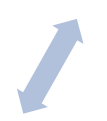

Radical Changes (R)

\section{Operations}

(O)
Overall

Performance (P) 


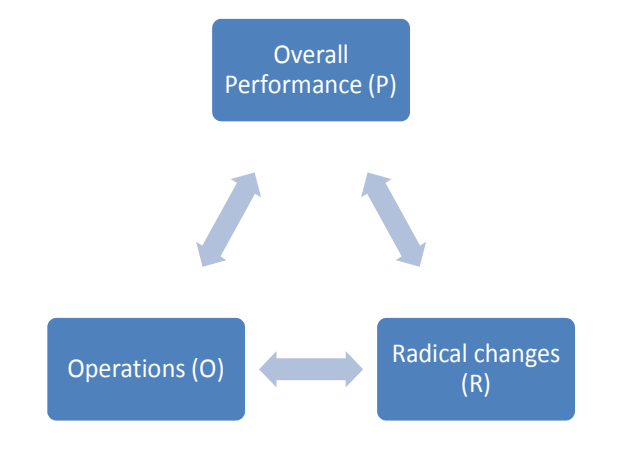

Figure2 (c) Relationships between CSFs - Implementation Triad

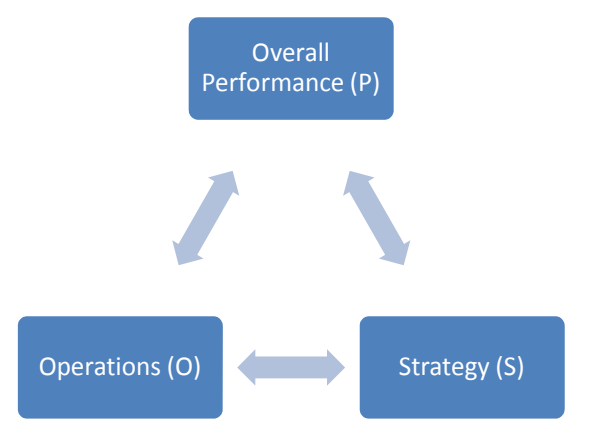

Figure 2 (d) Relationships between CSFs - Tactical Triad

Figure 2. Relationships between CSFs

1) Foundation Triad consists of strategy vector, radical change vector, and operation vector. This phase of the implementation cycle considers the initial relationship of top management with executives, communication, and management vision, assessment of customer requirement, developing BPR enablers, technology shift, customer acceptance, and formulation of desired performance results. Here the effort should be keep the vectors in equilibrium so that the base of pyramid remain horizontal and sides of triangle are equilateral.

2) Reliability Triad consists of strategy vector, operation vector, and its relationship with performance vector. The vectors are adjusted in such a way that the triad remains equilateral. It is very essential for stability of the pyramid.

3) Tactical Triad The performance, strategy, and radical change vectors enables the company to prepare tactical decisions. One of the challenges is on 'managing resistance to change'. Periodic feedback of the perception of changes will assist in finalizing the operation methodologies.

4) Implementation Triad Operation vector and strategy vector characterize the performance vector. It is the most difficult triad. Training is one of the most desirable construct for this phase.

\section{Hypothesis Formulation and Testing}

CSFs discussed above are dominant factors which play a significant role in the successful implementation of BPR. These are broad in nature and impact the long-term effectiveness of the company. They require a significant change in the manner in which the environment (market forces) changes. Further, to evaluate the impact of BPR implementation on the overall performance, following null hypotheses for strategy, radical changes, and operations are developed:

$\mathbf{H}_{\mathbf{0}}$. Strategic factors have a direct and positive effect on overall performance.

$\mathbf{H}_{\mathbf{0 R}}$. Radical change factors have a direct and positive effect on overall performance.

$\mathbf{H}_{\mathbf{0 O}}$. Operational factors have a direct and positive effect on overall performance.

In order to test the hypothesis and use the standard regression technique, all constructs were tested for normality. Kolmogorov-Smirnov Test (Table 8) for the constructs was done. It is evident from the results that there is no indication of construct data departing from normality. Table 9 is giving the correlation values between the constructs. Cohen's (1988) recommended considering values of ' $r$ ' between 0.1 to 0.3 as indicator of small correlation, ' $r$ ' between 0.3 to 0.5 as indicator of moderate correlation, and for ' $r$ ' above 0.5 is the indicator of strong correlation. Thus there is small correlation between strategy formulation and bringing radical changes in the organization (0.172), and moderate correlation between strategy formulation and implementation of operations (0.325). The correlation between strategy and performance as well as radical changes and performance is small ( 0.284 and 0.173 respectively). However, the value of correlation coefficient between operations construct and performance parameters is negative. It was further corroborated by examining the regression line of the constructs, shown in Figures 3(a) to 3(c). ' $t$ ' test was carried our for these constructs. For strategy and operations constructs, the 'p' value of .000 mean that the probability of randomly drawing a sample of 302 from a population with a mean of 3.50 and getting a sample a sample mean of 4.3 and 3.9 of strategy \& operations construct respectively by chance is $0.00 \%$. In other words, it is unlikely to have occurred by chance 
indicating a significant positive effect of strategy and operation constructs on performance evaluation. For radical changes construct, the value of ' $p$ ' is 0.003 , which is equivalent to 1.9 of critical value of ' $t$ ' distribution. This value is lesser than value of ' $t$ ' parameter, obtained from ' $t$ ' test (3.035). This finding indicates that null hypothesis of radical change construct is also true. This is a good sign reflecting that strategy formulation, managing to adopt changes, and devising operations to achieve the desired performance are the strong pillars of government organizations. However, the overall impact of CSFs is not the effect of coherent vectors. There is mismatch among the functioning of CSFs, which is like cancelling the positive effect of one CSF by another CSF which is misdirected. This leads to tilting of the model represented in Figure 1. This is unstable position. It does not lead to overall enhancement of performance. A schematic representation is shown in Figure 4.

Table 8A. One-sample kolmogorov-smirnov test - strategy

\begin{tabular}{llc}
\hline & & Strategy \\
\hline $\mathrm{N}$ & & 302 \\
\multirow{2}{*}{ Normal Parameters(a,b) } & Mean & 4.2775 \\
& Std. Deviation & .48631 \\
Most $\quad$ Extreme & Absolute & .159 \\
Differences & Positive & .091 \\
& Negative & -.159 \\
Kolmogorov-Smirnov Z & & 2.755 \\
Asymp. Sig. (2-tailed) & & .000 \\
\hline
\end{tabular}

a Test distribution is Normal.

b Calculated from data.

Table 8B. One-sample kolmogorov-smirnov test - radical changes

\begin{tabular}{llc}
\hline & & Radical Changes \\
\hline $\mathrm{N}$ & & 302 \\
Normal Parameters(a,b) & Mean & 3.5904 \\
& Std. Deviation & .51762 \\
Most $\quad$ Extreme & Absolute & .157 \\
Differences & Positive & .157 \\
& Negative & -.129 \\
Kolmogorov-Smirnov Z & & 2.736 \\
Asymp. Sig. (2-tailed) & & .000
\end{tabular}

a Test distribution is Normal.

b Calculated from data.

Table 8C. One-sample kolmogorov-smirnov test - performance

\begin{tabular}{llc}
\hline & & Performance \\
\hline $\mathrm{N}$ & & 302 \\
Normal Parameters(a,b) & Mean & 3.9627 \\
& Std. Deviation & .70509 \\
Most $\quad$ Extreme & Absolute & .089 \\
Differences & Positive & .082 \\
& Negative & -.089 \\
Kolmogorov-Smirnov Z & & 1.540 \\
Asymp. Sig. (2-tailed) & & .017 \\
\hline
\end{tabular}

a Test distribution is Normal.

b Calculated from data. 
Table 9. Correlation values

\begin{tabular}{|c|c|c|c|c|c|}
\hline & & Strategy & Radical Changes & Operations & Performance \\
\hline \multirow[t]{5}{*}{ Strategy } & $\begin{array}{l}\text { Pearson } \\
\text { Correlation }\end{array}$ & 1 & $.172(* *)$ & $.325(* *)$ & $.284(* *)$ \\
\hline & Sig. (1-tailed) & . & .001 & .000 & .000 \\
\hline & $\begin{array}{l}\text { Sum of Squares } \\
\text { and } \\
\text { Cross-products }\end{array}$ & 71.187 & 13.061 & 31.683 & 34.296 \\
\hline & Covariance & .237 & .043 & .105 & .114 \\
\hline & $\mathrm{N}$ & 302 & 302 & 302 & 302 \\
\hline \multirow[t]{5}{*}{ Radical Changes } & $\begin{array}{l}\text { Pearson } \\
\text { Correlation }\end{array}$ & $.172(* *)$ & 1 & $.210(* *)$ & $.173(* *)$ \\
\hline & Sig. (1-tailed) & .001 & . & .000 & .001 \\
\hline & $\begin{array}{l}\text { Sum of Squares } \\
\text { and } \\
\text { Cross-products }\end{array}$ & 13.061 & 80.646 & 21.810 & 22.163 \\
\hline & Covariance & .043 & .268 & .072 & .074 \\
\hline & $\mathrm{N}$ & 302 & 302 & 302 & 302 \\
\hline \multirow[t]{5}{*}{ Operations } & $\begin{array}{l}\text { Pearson } \\
\text { Correlation }\end{array}$ & $.325(* *)$ & $.210(* *)$ & 1 & -.012 \\
\hline & Sig. (1-tailed) & .000 & .000 & . & .415 \\
\hline & $\begin{array}{l}\text { Sum of Squares } \\
\text { and } \\
\text { Cross-products }\end{array}$ & 31.683 & 21.810 & 133.367 & -2.052 \\
\hline & Covariance & .105 & .072 & .443 & -.007 \\
\hline & $\mathrm{N}$ & 302 & 302 & 302 & 302 \\
\hline \multirow[t]{5}{*}{ Performance } & $\begin{array}{l}\text { Pearson } \\
\text { Correlation }\end{array}$ & $.284(* *)$ & $.173(* *)$ & -.012 & 1 \\
\hline & Sig. (1-tailed) & .000 & .001 & .415 & \\
\hline & $\begin{array}{l}\text { Sum of Squares } \\
\text { and } \\
\text { Cross-products }\end{array}$ & 34.296 & 22.163 & -2.052 & 204.534 \\
\hline & Covariance & .114 & .074 & -.007 & .680 \\
\hline & $\mathrm{N}$ & 302 & 302 & 302 & 302 \\
\hline
\end{tabular}

** Correlation is significant at the 0.01 level (1-tailed).

Table 10(a). ' $T$ ' test - strategy constructs

One-Sample Statistics

\begin{tabular}{rrrrr}
\hline & N & Mean & Std. Deviation & Std. Error Mean \\
\hline Strategy & 302 & 4.2775 & .48631 & .02798 \\
\hline
\end{tabular}

One-Sample Test

\begin{tabular}{lllcccc}
\hline & & \multicolumn{3}{c}{ Test Value $=3.5$} \\
\hline & \multirow{2}{*}{$\mathrm{t}$} & $\mathrm{df}$ & Sig. (2-tailed) & $\begin{array}{c}\text { Mean } \\
\text { Difference }\end{array}$ & \multicolumn{2}{c}{$\begin{array}{c}\text { 95\% Confidence Interval of } \\
\text { the Difference }\end{array}$} \\
\cline { 6 - 7 } & & & & & Lower & Upper \\
\hline Strategy & 27.783 & 301 & .000 & .77748 & .7224 & .8326 \\
\hline
\end{tabular}


Table 10(b). ' $\mathrm{T}$ ' test - operations constructs

One-Sample Statistics

\begin{tabular}{lrrrc}
\hline & $\mathrm{N}$ & Mean & Std. Deviation & Std. Error Mean \\
\hline Operations & 302 & 3.9387 & .66564 & .03830 \\
\hline
\end{tabular}

One-Sample Test

\begin{tabular}{|c|c|c|c|c|c|c|}
\hline & \multicolumn{6}{|c|}{ Test Value $=3.5$} \\
\hline & \multirow[t]{2}{*}{$\mathrm{t}$} & \multirow[t]{2}{*}{ df } & \multirow[t]{2}{*}{ Sig. (2-tailed) } & \multirow[t]{2}{*}{$\begin{array}{c}\text { Mean } \\
\text { Difference }\end{array}$} & \multicolumn{2}{|c|}{$\begin{array}{l}\text { 95\% Confidence Interval of } \\
\text { the Difference }\end{array}$} \\
\hline & & & & & Lower & Upper \\
\hline Operations & 11.454 & 301 & .000 & .43874 & .3634 & .5141 \\
\hline
\end{tabular}

Table 10(c). ' $\mathrm{T}$ ' test - radical changes constructs

One-Sample Statistics

\begin{tabular}{lcccc}
\hline & $\mathrm{N}$ & Mean & Std. Deviation & Std. Error Mean \\
\hline Radical Changes & 302 & 3.5904 & .51762 & .02979 \\
\hline
\end{tabular}

One-Sample Test

\begin{tabular}{lcccccc}
\hline & \multicolumn{8}{c}{ Test Value $=3.5$} \\
\cline { 3 - 7 } & \multirow{2}{*}{$\mathrm{t}$} & $\mathrm{df}$ & Sig. (2-tailed) & Difference & \multicolumn{2}{c}{$\begin{array}{c}\text { 95\% Confidence Interval of the } \\
\text { Difference }\end{array}$} \\
\cline { 5 - 7 } & & & & & Lower & Upper \\
\hline Radical Changes & 3.035 & 301 & .003 & .09040 & .0318 & .1490 \\
\hline
\end{tabular}

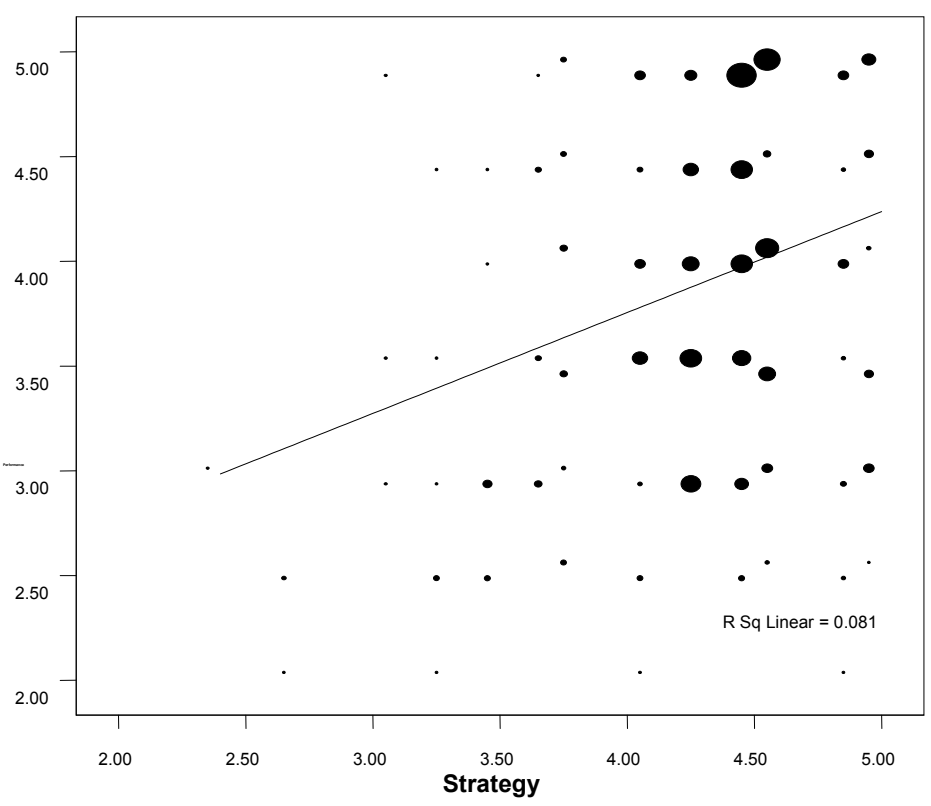

Figure 3(a). Regressions between strategy \& performance 


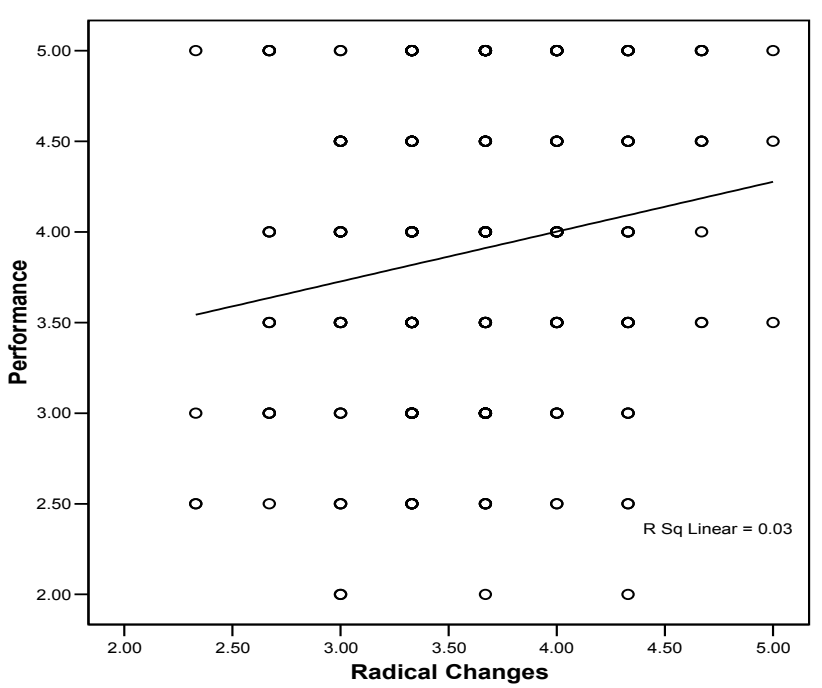

Figure 3(b). Regressions between radical changes \& performance

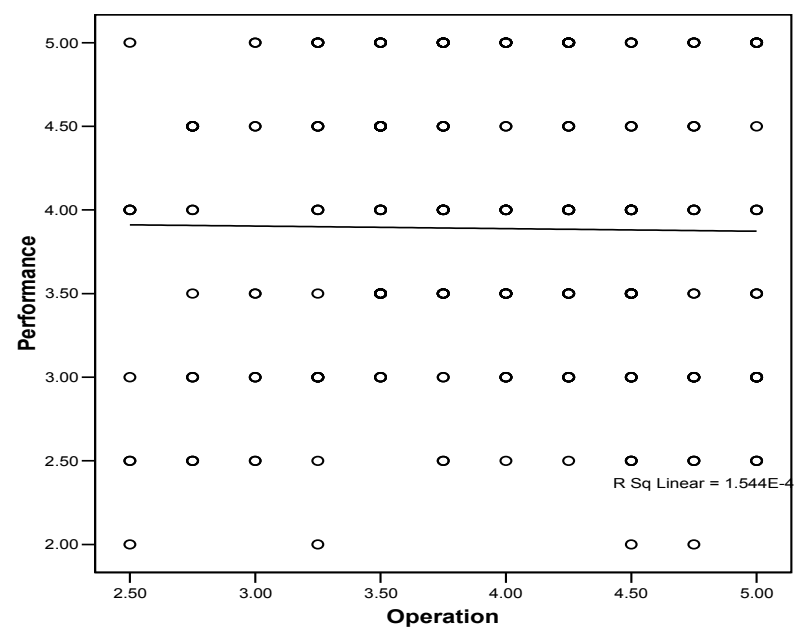

Figure 3(c). Regressions between operations \& performance

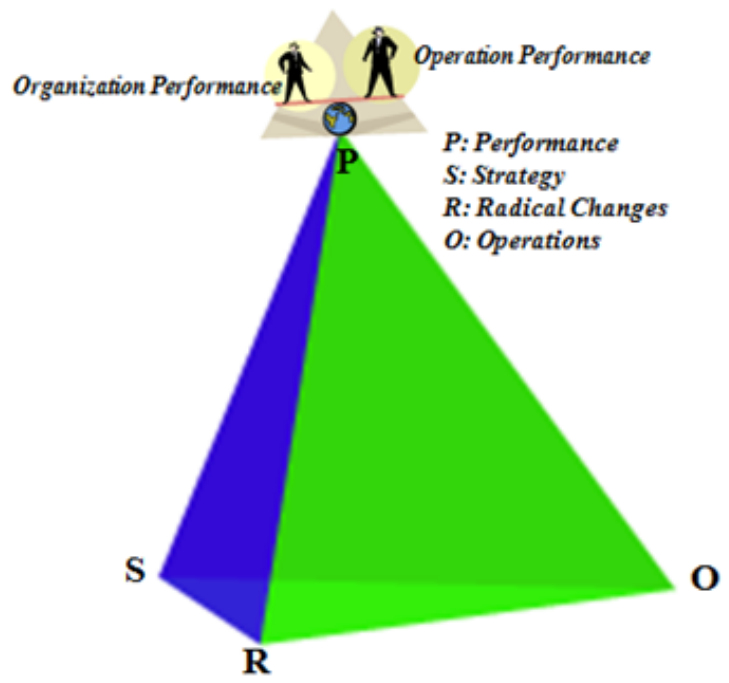

Figure 4. Schematic representation of integrated effect of CSF on SWATI model - unstable state 


\section{Analysis}

The most significant difference between private sector and public sector is in efficiency, accountability and initiative. In private sector, the focus is on efficiency and effectiveness. Productivity is paramount, and enterprise and intelligent risk-taking are encouraged. The objective is to increase revenues and profits by doing things faster, better and cheaper, and by meeting customer's needs. Strategic and tactical decisions are made and closely monitored by a team of people who have similar values and the same goals. One of the main problems of the government organization is the multitude of purposes the organizations have to serve. There is unpredictability about who will report to whom. There is a deep culture of risk aversion. For example, the top management looking for radical quality and productivity improvements may shift the focus from true reengineering to least resistance approach of process improvement. The focus moves to the improvement in the efficiency of those processes and seek solution of superficial problems, which can still be defended as a process-focused approach to improvement. Argyris (1977) opines that managers in government are in "double bind", which means there is a tendency to either "hide errors"; or "reveal errors". If managers choose the first norm they know that what they do is necessary yet counterproductive to the organisation. If they choose the second norm, they expose a whole network of camouflage and deception. The choice often lies on the less risky norm that says "hide errors". In double bind situations, managers at first consciously refuse to admit that there are problems. This approach is taken to avoid the consequences of having to deal with those problems. Then, they gradually start to lose sight of those problems, as if they did not actually exist. Managers, then, shift their focus to less problematic intermediate goals which are initially used as an excuse, but soon become "real goals". Private sector approaches for market solutions by ensuring optimum use of resources and efforts and achieving impressive gains in wealth and productivity.

\section{Conclusion}

The public organizations have higher social obligations and public accountability than the private sector. BPR systems have been considered risky projects with all the failure stories circulating in the media. Now that many different kinds of public organizations around the world have successful gone through BPR implementation through ERP process, it has started to push large scale IT investments on the agenda in the public sector. Robert MacIntosh (2003) observed that public organizations often have to function under tighter resource restrictions even though a larger investment would be fully justified. She-I Chang, Guy Gable, Errol Smythe and Greg Timbrell (2000) studied public sector implementation issues in five government agencies in Queensland, Australia. They confirmed that the most problematic issue regarding large scale implementations are within the domain of knowledge and change management.

Sameer Sachdev (2002) wrote a white paper on 'E - Governance of Strategy in India', discussing the broad issues surrounding the readiness for E-Governance in India. It looks into the relationship and application of information, knowledge, information systems, and information and communication technologies in the process of government. This is a good indicator as the government has realized the necessities of reforming its units to improve performance.

McAdam and Donaghy (1999) observed from a single case study that private and public sector CSFs do not differ all that much. Further research has shown that application of private sector methodologies in public sector settings have positive results. It might be that there is more of a psychological and cultural change effort needed than a technical to radically change the processes in government units. One must still keep in mind that there is not a definitive methodology that will guarantee a successful BPR project. Only tools and recommendations that aid the organization in embracing the change with as little friction as possible are advisable to be used. Too light hearted approach will result in failure.

In this paper we have studied the interrelations among CSFs to BPRs and have shown that it is necessary to monitor the contribution of each CSF so that overall performance is having a synergy effect of the contribution of each CSF. There are many different performance measurement frameworks, such as the balanced scorecard, activity based costing, competitive benchmarking, resource based value, and shareholder value added. Each of these provides different lens through which to view an organization's performance. The most suitable measurement framework for the select organization is optimization of resources.

Ostroff (2006) identified five principles that can lead to successful change effort in public sectors. These are: improve performance against agency mission, win over stake holders, create a road map, take a comprehensive approach, and be a leader not a bureaucrat. Public sector units may appear to be mysterious places; but effortless reforms can be brought. What is required an objective approach to examine the problems in implementing reforms. Some of the generic techniques, as being implemented in private sectors, may not succeed in public 
sector as they need to be innovative and tailor made.

\section{Suggestion for Further Research}

Organizations should not be apprehensive to implement radical changes as BPR can actually lead to competitive advantage. The key areas of improvements in government organizations can be achieved in process quality, resource optimization, production efficiency, and customer service. The study was empirical in nature and further research need to be done using quantitative methods by taking information of CSFs before and after completion of BPR implementation. In the study, the focus was on development of a conceptual model which can link the CSFs to organization and operation performance. There is scope to link the key success factors and performance for competitive advantage and test them for statistical significance.

Further, since ERP is widely being utilized in private sector for streamlining processes and information, it would be nice to carry out studies on profitability of implementing ERP in the public sector.

\section{References}

Ahmad, H., Francis, A., \& Zairi, M. (2007). Business process reengineering: critical success factors in higher education. Business Process Management Journal, 13(3), 451-467. http://dx.doi.org/10.1108/14637150710752344

Al Mashari M., \& Zairi M. (2000). Revisiting BPR - a holistic review of practice and development. Business Process Management Journal, 6(1), 10-42. http://dx.doi.org/10.1108/14637150010283045

Al-Mashari, M., \& Zairi, M. (1999). Business process reengineering implementation processes: an analysis of key success and failure factors. Business Process Management Journal, 5(1), 87-112. http://dx.doi.org/10.1108/14637159910249108

Argyris, C. (1977). Double Loop Learning Organizations. Harvard Business Review, September- October, 115-125.

Beaumont, N., Schroder, R., \& Sohal, A. (2002). Do foreign-owned firms manage advanced manufacturing technology better? International Journal of Operations \& Production Management, 22(7), 759-71. http://dx.doi.org/10.1108/01443570210433535

Birch C. (2000). Future Success: A Balanced Approach to measuring and improving success in your organization. Prentice Hall.

Black S., \& Porter L. (1996). Identification of critical factors of TQM. Decision Sciences, 27(1), 1-21. http://dx.doi.org/10.1111/j.1540-5915.1996.tb00841.x

Brah, S., Tee, S., \& Rao, B. (2002). Relationship between TQM and performance of Singapore companies. International Journal of Quality \& Reliability Management, 19(4), 356-79. http://dx.doi.org/10.1108/02656710210421553

Chan, C. K., \& Lee, C. (2005). Successful Strategies in Supply Chain Management. London: Idea Group Publishing.

Chang R. Y. (1994). Improve processes, reengineer them, or both? Training \& Development, 48(3), 54-58.

Chang, She I., Gable, Guy., Smythe, Errol., \& Timbrell, G. (2000). A Delphi examination of public sector ERP implementation issues. Proceedings 21st International Conference on Information Systems, 494-500.

Cohen S., \& Brand R. (1993). Total quality management in Government: A practical guide for real world. Josey - Bass.

Cohen, J. (1988). Statistical Power Analysis for the Behavioral Sciences. New York, NY: Academic Press.

Cortina, J. M. (1993). What is coefficient alpha? Journal of Applied Psychology, 78, 98-104. http://dx.doi.org/10.1037/0021-9010.78.1.98

Davenport T. (1993). Process innovation: reengineering work through information technology. Boston MA: Harvard Business School Press.

Doherty N., \& Horsted J. (1996). Reengineering people - the forgotten survivors. Business change and Reengineering,
http//dx

http://dx.doi.org/10.1002/(SICI)1099-0828(199601)3:1<39::AID-BCR49>3.0.CO;2-3

Flynn D., \& Arce E. (1997). A CASE Tool to support critical success factors analysis in IT planning and 
requirements determination. Information and Software Technology, 39, 311-321. http://dx.doi.org/10.1016/S0950-5849(96)01150-0

Gholamreza Jamali, Mohammad Ali Abbaszadeh, Mehran Ebrahimi, \& Tahereh Maleki. (2011). Business Process Reengineering Implementation: Developing a Causal Model of Critical Success Factors. International Journal of e-Education, e-Business, e-Management and e-Learning, 1(5).

Gates, S. (1999). Aligning Strategic Performance Measures and Results. The Conference Board, New York, US.

Hair, J. F., Anderson, R. E., Tatham, R. L., \& Black, W. C. (1992). Multivariate Data Analysis (3rd Ed.). Maxwell Macmillan International, Sydney.

Hammer M., \& Champy J. (1993). Reengineering the Corporation: A Manifesto for Business Revolution (p. 35). London: Nicholas Brealey Publishing.

Huq, Z. (2005). Managing change: a barrier to TQM implementation in service industries. Managing Service Quality, 15(5), 452-69. http://dx.doi.org/10.1108/09604520510617301

Hodgson, K. (1994). Customer Service in the Stamp Office. In R. Lovell (Ed.), Managing Change in the New Public Sector (pp. 319-333). Longman, Harlow Essex, England.

Ittner, C. D., Larcker, D. F., \& Randall, T. (2003). Performance Implications of Strategic Performance Measurement in Financial Service Firms'. Accounting, Organizations and Society, 28(7-8), 715-741. http://dx.doi.org/10.1016/S0361-3682(03)00033-3

Koh, S., Demirbag, M., Bayraktar, E., Tatoglu, E., \& Zaim, S. (2007). The impact of supply chain management practices on performance of SMEs. Industrial Management \& Data Systems, 107(1), 103-24. http://dx.doi.org/10.1108/02635570710719089

Kotey, B., \& Slade, P. (2005). Formal human resource management practices in small growing firms. Journal of Small Business Management, 43(1), 16-40. http://dx.doi.org/10.1111/j.1540-627X.2004.00123.x

MacIntosh, R. (2003). BPR: alive and well in the public sector. International Journal of Operations \& Production Management, 23(3), 327-344. http://dx.doi.org/10.1108/01443570310462794

McAdam, R., \& Donaghy, J. (1999). Business process re-engineering in the public sector - A study of staff perceptions and critical success factors. Business Process Management, 5(1), 33-49. http://dx.doi.org/10.1108/14637159910249135

Malhotra, M. K., Grover, V., \& Desilvio, M. (1996). Reengineering the new product development process - a framework for innovation and flexibility in high technology firms. OMEGA - International Journal of Management Science, 24(4), 426-441.

Neely, A. D. (1998). Measuring Business Performance: Why, What and How. London: Economist Books.

Nunally, J. C. (1978). Psychometric Theory (2nd Ed.). New York: McGraw Hill.

Oakland, John S., \& Peter Morris. (1997). TQM: A pictorial guide for managers. Oxford: ButterworthHeinemann.

Ostraff Frank. (2006). Change management in government. Harvard Business Review, May, 1-8.

Otley, D. T. (1999). Performance Management: a Framework for Management Control Systems Research. Management Accounting Research, 10(4), 363-382. http://dx.doi.org/10.1006/mare.1999.0115

Peffers K., Gengler C., \& Tuunanen T. (2003). Extending Critical Success Factors Methodology to Facilitate Broadly Participative Information Systems Planning. Journal of Management Information Systems, 20(1), 51-85.

Pinto J., \& Slevin D. (1987). Critical Factors in Successful Project Implementation. IEEE Transactions on Engineering Management, 34(1), 22-27.

Raff, M., \& Beedon J. (1994). Total Quality Management in the West Midlands Employment Service. In R. Lovell (Ed.), Managing Change in the New Public Sector (pp. 294-318). Longman, Harlow Essex, England.

Ramamurthy, K. (1995). The influence of planning on implementation success of advanced manufacturing technology. IEEE Transactions on Engineering Management, 42(1), 62-73. http://dx.doi.org/10.1109/17.366406

Ringim Kabiru J., Razalli Mohd R., \& Hasnan N. (2012). Critical Success factors for Business Process Management for Small and Medium Banks in Nigeria. Business and Management Review, 2(1), 83-91. 
Sachdev Sameer. (2002). Whitr paper on E - Governance strategy in India.

Snow C. C., \& Hrebniak L. (1980). Strategy, distinctive competence, and organizational performance. Administrative Science Quarterly, 25, 317-335. http://dx.doi.org/10.2307/2392457

Steers R. M. (1977). Organizational Effectiveness: A Behavioural View. The Goodyear series in management and organizations, Santa Monica, CA: Goodyear Publishing.

Tamimi, N., \& Sebastianelli R. (2003). Understanding the obstacles to TQM success. The Quality Management Journal, 10(3), 45.

Terziovski, M., Samson, D., \& Dow, D. (1997). The business value of quality systems certification: Evidence from Australia and New Zealand. Journal of Operations Management 15(1), 1-18. http://dx.doi.org/10.1016/S0272-6963(96)00103-9

Vantrappen, H. (1992). Creating customer value by streamlining business processes. Long Range Planning, 25(1), 53-62. http://dx.doi.org/10.1016/0024-6301(92)90310-X

Venkatraman N., \& Ramanujam V. (1986). Measurement of Business Performance in Strategy Research: A Comparison of Approaches. Academy of Management Review, 11(4), 801-814.

Yusof, S., \& Aspinwall, E. (2000). Critical success factors in small and medium enterprises: survey results. Total Quality Management, 11(4), 248-462. http://dx.doi.org/10.1080/09544120050007760 